\title{
3D brain tissue physiological model with co-cultured primary neurons and glial cells in hydrogels
}

Journal of Tissue Engineering Volume II: I-13 (C) The Author(s) 2020 Article reuse guidelines: sagepub.com/journals-permissions DOI: 10.1 |77/204|73|42096398| journals.sagepub.com/home/tej

(S)SAGE

\author{
Ilaria Raimondi', Marta Tunesi' (D, Gianluigi Forloni' ${ }^{2}$, \\ Diego Albani ${ }^{2}$ and Carmen Giordano'
}

\begin{abstract}
Recently, researchers have focused on the role of gut microbiota on human health and reported the existence of a bidirectional relationship between intestinal microbiota and the brain, referred to as microbiota-gut-brain axis (MGBA). In this context, the development of an organ-on-a-chip platform recapitulating the main players of the MGBA would help in the investigations of the biochemical mechanisms involved. In this work, we focused on the development of a new, hydrogel-based, 3D brain-like tissue model to be hosted in the brain compartment of the aforementioned platform. We previously cultured primary mouse microglial cells, cortical neurons and astrocytes independently, once embedded or covered by a millimeter layer of two selected collagen-based hydrogels. We evaluated cell metabolic activity up to 2 I days, cell morphology, spatial distribution and synapse formation. Then, we exploited the best performing culturing condition and developed a more complex brain-like tissue model based on the co-culture of cortical neurons and glial cells in physiological conditions. The obtained results indicate that our 3D hydrogel-based brain tissue model is suitable to recapitulate in vitro the key biochemical parameters of brain tissue.
\end{abstract}

\section{Keywords}

Brain in vitro models, neural cells, 3D culture, hydrogels, collagen

Date received: 7 June 2020; accepted: 13 September 2020

\section{Introduction}

Mammalian brain tissue is complex, and challenging to model in vitro. However, the investigations of several pathophysiologic mechanisms would greatly benefit from the availability of reliable cell-based systems featuring at least the main brain cell populations, neurons and glial cells. An example where such models could help move our knowledge forward is the microbiota-gut-brain axis (MGBA). In the last few years, the number of publications on the role of gut microbiota in human health has increased significantly and researchers have reported a bidirectional relationship between gut microbiota and the brain. It exploits several communication pathways, such as the release of microbial factors, intestinal hormones and cytokines from the immune system. ${ }^{1-4}$ In this context, the Authors aim at developing an optically accessible multi-organ-on-a-chip platform hosting advanced two- (2D), suspended, and three-dimensional (3D) in vitro models to recapitulate the main players of the MGBA, such as the microbiota, the gut, the immune system, the blood-brain barrier and the brain, in physiological and pathological conditions. ${ }^{4}$ In the present work, we focused on the setting up of a millimeter-thick brain-like tissue model potentially suitable for dynamic culture in a recently developed optically accessible organ-on-a-chip (OOC) device. ${ }^{5}$

In the last decade, OOC technology has seen considerable improvements for its potential to reduce animal studies for drug development and toxicity testing. ${ }^{6}$ Its reliability and reproducibility offer substantial advantages for tissue

\footnotetext{
'Department of Chemistry, Materials and Chemical Engineering "G. Natta", Politecnico di Milano, Milan, Italy

2Department of Neuroscience, Istituto di Ricerche Farmacologiche Mario Negri IRCCS, Milan, Italy

Corresponding author:

Carmen Giordano, Department of Chemistry, Materials and Chemical Engineering “G. Natta”, Politecnico di Milano, P.za Leonardo da Vinci 32, 20133 Milan, Italy.

Email: carmen.giordano@polimi.it
} 
and disease modeling, ${ }^{7,8}$ overcoming the limitations of $2 \mathrm{D}$ static cultures.

Despite their simplicity compared to the in vivo situation, 3D models have significantly contributed to the recapitulation of tissue properties, cell-cell contacts and cell-extracellular matrix (ECM) interactions. ${ }^{9-12}$ Organoids, miniaturized self-organized tissue cultures from stem cells, are among the most promising 3D models for brain representation. ${ }^{13,14}$ They have been employed to study brain development and organization, as well as neurological diseases. ${ }^{15}$ However, they lack cell aging ${ }^{16}$ and internal vascularization, inducing necrosis. ${ }^{17}$ They are hard to grow, labor-intensive and time-consuming, all major disadvantages for investigations of disease pathways and drug targets. $^{18}$

As an alternative to organoids, hydrogels are excellent candidates to mimic the ECM of soft tissues and have emerged for the development of 3D brain-like tissue models. ${ }^{19}$ Their stiffness is a key factor in the regulation of neuronal cell shape, viability, expression, migration and differentiation, both in $2 \mathrm{D}^{20,21}$ and $3 \mathrm{D}$ conditions. ${ }^{22}$ Several studies have indicated that softer gels promote neurite outgrowth, ${ }^{23}$ while glial cells prefer a stiffer microenvironment. ${ }^{24}$ However, some studies reported that soft hydrogels support astrocyte differentiation and survival. ${ }^{25}$

Microglia, the resident immune cells of the central nervous system (CNS), play a key role in the maintenance of CNS homeostasis and in the management of tissue response to injury. ${ }^{26}$ They are involved in monitoring synapse extension ${ }^{27}$ and remodeling during development, ${ }^{28}$ they contribute to neuroprotection and regeneration by releasing cytokines, molecules and other neurotrophic factors. ${ }^{29}$ Studies coupling microglia and hydrogels are not numerous. Up to now, they have focused on hydrogel effects on cell morphology, adhesion and motility ${ }^{26}$ and cytokine release. ${ }^{30}$

Hydrogels have been used to culture neural cells in different 3D conditions. Ylä-Outinen et al. cultured human embryonic stem cell-derived neural cells up to four weeks under PuraMatrix TM hydrogels. The cells were cultured on laminin-coated microplates for some days, then covered with a hydrogel layer, or encapsulated into the hydrogels after mixing with the polymer solution. ${ }^{31} \mathrm{Xu}$ et al. proposed a sandwich-based condition, in which the cells were grown at the interface of two hydrogel layers for 21 days. ${ }^{32}$

For a long time, neurons have been cultured alone in biomaterials or devices and the role of glial cells has gone into the background. Now it has clearly emerged that the advanced modeling of brain-like tissues depends on the co-culture of different neural cell populations and the investigations of their interactions. ${ }^{15}$ For instance, astrocytes play key roles in neural functions, such as axon growth and direction, synaptogenesis, formation of the blood-brain barrier, and inflammatory responses. ${ }^{33}$ Their morphology, proliferation rate and marker expression are governed by $2 \mathrm{D}$ or $3 \mathrm{D}$ culture conditions, with $3 \mathrm{D}$ cultures providing conditions more similar to the in vivo situation and allowing early postnatal cells to transit to the differentiated stellate morphology. ${ }^{33}$

Starting from the literature and our previous works with immortalized neuronal cells, ${ }^{34,35}$ we employed semi-interpenetrating polymer networks (semi-IPNs) prepared by promoting collagen (COLL) fibrillogenesis in the presence of hyaluronic acid (HA) or poly(ethylene glycol) (PEG) to develop a millimeter-thick brain-like tissue model based on the co-culture of neurons and glial cells. To set up a physiological model, we started from single cultures of primary mouse microglial cells, cortical neurons and astrocytes and compared two culture conditions: (a) a layeredbased condition, where a layer of hydrogel covers the cells attached to the microplate; and (b) an embedded-based condition, where the cells are evenly distributed in the polymer solutions during hydrogel preparation. For both conditions, we recorded cell growth and survival up to 21 days, cell morphology and distribution, and synapse formation in neuronal networks. After selecting the most suitable condition, we proposed a more advanced model, co-culturing neurons and glial cells in the embedded-based condition.

\section{Materials}

For hydrogel preparation, we purchased reagents from Sigma-Aldrich (St. Louis, MO, USA). We obtained reagents for cell culture from Thermo Fisher Scientific (Waltham, MA, USA) and plasticware from Corning ${ }^{\circledR}$ (Corning, NY, USA).

\section{Experimental procedures}

\section{Hydrogel preparation}

For the development of 3D models, we cultured brain cells (as single cultures or co-cultures) in semi-IPNs based on COLL and HA $\left(\mathrm{M}_{\mathrm{w}}=1 \cdot 10^{5} \mathrm{Da}\right.$, Altergon Italia, Morra De Sanctis, Italy) or COLL and PEG. We used PEG with two molecular weights $\left(\mathrm{M}_{\mathrm{w}}\right): 1.945 \mathrm{kDa}$ (referred to as $\mathrm{PEG}_{2000}$ ) and $3.270 \mathrm{kDa}$ (referred to as $\mathrm{PEG}_{3350}$ ).

For all the formulations, we diluted 8 parts (v/v) type I COLL solution $(3 \mathrm{mg} / \mathrm{mL})$ from bovine skin with 1 part $(\mathrm{v} / \mathrm{v}) \mathrm{NaOH} 0.1 \mathrm{~N}$ and 1 part (v/v) 10x phosphate-buffered saline solution (PBS). For COLL-HA gels, we mixed 1 part (v/v) COLL solution with 1 part (v/v) HA solution $\left(5 \mathrm{mg} / \mathrm{mL}\right.$ in water, autoclaved at $121^{\circ} \mathrm{C}$ for $15 \mathrm{~min}$ or with an equivalent time $\mathrm{F}_{0}$ equal to 13). For COLL-PEG gels, we mixed 3 parts $(\mathrm{v} / \mathrm{v})$ COLL solution with 1 part $(\mathrm{v} / \mathrm{v})$ PEG solution $(2.4 \mathrm{mg} / \mathrm{mL}$ in saline, autoclaved). To promote COLL fibrillogenesis, we incubated the polymer solutions at $37^{\circ} \mathrm{C}$ for about $1.5 \mathrm{~h}$. 
To select the most suitable conditions to establish a brain-like tissue model based on the co-culture of neurons and glial cells, we plated the cells and covered with a $1.5 \mathrm{~mm}$-thick hydrogel layer (layered condition) or we mixed 1 part (v/v) cell suspension with 9 parts $(\mathrm{v} / \mathrm{v})$ polymer solutions, and plated $1.5 \mathrm{~mm}$-thick samples (embedded condition).

\section{Primary brain cell cultures}

Primary cells were harvested from CD-1 mice (Charles River Laboratories, Calco, Italy). We harvested microglia from 2 to 3 days postnatal mice, and cortical neurons and astrocytes from 2-4 days postnatal mice. We cultured the cells at $37{ }^{\circ} \mathrm{C}, 5 \% \mathrm{CO}_{2}$.

\section{D microglial cells}

We prepared microglial cultures according to previous studies. ${ }^{36,37}$ We removed the meninges and dissected a slice of cortex, minced it, digested it with $0.25 \%$ trypsin supplemented with $0.01 \%$ DNase I and pipetted it dropwise onto a $70-\mu \mathrm{m}$ filter. We suspended the cells in Dulbecco's modified eagle medium/Nutrient mixture F-12 Ham (DMEM/F-12), supplemented with $10 \%$ fetal bovine serum (FBS), $100 \mathrm{U} / \mathrm{mL}$ gentamicin, $100 \mathrm{U} / \mathrm{mL}$ penicillin and $100 \mu \mathrm{g} / \mathrm{mL}$ streptomycin, and plated them in flasks. When the cells were confluent (after about 15 days), we incubated them with $0.25 \%$ trypsin for $1.5 \mathrm{~h}$, shaking the flasks every $30 \mathrm{~min}$. We washed the adherent microglial cells twice with medium, detached them with $0.25 \%$ trypsin- $0.02 \%$ EDTA, centrifuged them and suspended them in medium.

For layered conditions, we plated 63,000 cells $/ \mathrm{cm}^{2}$ and covered them with a $1.5 \mathrm{~mm}$-thick hydrogel layer. As controls, we plated 63,000 cells $/ \mathrm{cm}^{2}$ on poly-L-lysine coated microplates. For embedded conditions, we mixed 158,000 cells $/ \mathrm{cm}^{2}$ with the polymer solutions and plated $1.5 \mathrm{~mm}$ thick samples.

For both conditions, after COLL fibrillogenesis we added culture medium and changed it every 2 days.

\section{$3 D$ cortical neurons}

We harvested primary cortical neurons according to Restelli et al..$^{38}$ Briefly, we removed the meninges, dissected small slices of cortex and incubated them at $34{ }^{\circ} \mathrm{C}$ for $30 \mathrm{~min}$ in dissociation medium supplemented with $20 \mathrm{U} / \mathrm{mL}$ papain. We added $0.5 \mathrm{mg} / \mathrm{mL}$ trypsin inhibitor and dissociated the tissue with a Pasteur pipette. We suspended the cells in Neurobasal medium supplemented with $2 \%$ B27, $2 \mathrm{mM}$ L-glutamine, $100 \mathrm{U} / \mathrm{mL}$ penicillin and $100 \mu \mathrm{g} / \mathrm{mL}$ streptomycin.

For layered conditions, we plated 242,000 neurons $/ \mathrm{cm}^{2}$, incubated them for $2 \mathrm{~h}$ at $37{ }^{\circ} \mathrm{C}$, and covered them with a $1.5 \mathrm{~mm}$-thick hydrogel layer. As controls, we plated $242,000 \mathrm{cells} / \mathrm{cm}^{2}$ on poly-D-lysine coated microplates.
For embedded conditions, we mixed $315,000 \mathrm{cells} / \mathrm{cm}^{2}$ with the polymer solutions and plated samples of $1.5 \mathrm{~mm}$ thick. For both conditions, after COLL fibrillogenesis we added culture medium and refreshed it $(50 \% \mathrm{v} / \mathrm{v})$ every 2-3 days.

\section{D astrocytes}

We dissected a part of the cerebral cortex, removed the meninges and collected the tissue in Hanks' balanced salt solution (HBSS) without calcium chloride and magnesium, supplemented with $2 \mathrm{mM}$ Hepes, $100 \mathrm{U} / \mathrm{mL}$ penicillin and $100 \mu \mathrm{g} / \mathrm{mL}$ streptomycin. We incubated it in $0.25 \%$ trypsin- $0.02 \%$ EDTA for $20 \mathrm{~min}$, added complete medium (Minimum Essential medium supplemented with $10 \%$ FBS, $6 \mathrm{~g} / \mathrm{L}$ D-glucose, $100 \mathrm{U} / \mathrm{mL}$ penicillin and $100 \mu \mathrm{g} / \mathrm{mL}$ streptomycin) and dissociated it mechanically with a Pasteur pipette. We pipetted it dropwise onto a $40-\mu \mathrm{m}$ nylon filter, centrifuged it, suspended it in complete medium and plated it in poly-L-lysine coated flasks.

When the mixed primary glial culture was confluent (after about 20days), we shook the flasks overnight $(220 \mathrm{rpm})$ and changed the medium. To obtain a purified astrocyte culture, the same or the next day we added L-leucine methyl ester $(60 \mathrm{mM})$ to each flask for $90 \mathrm{~min}$ to inhibit microglial growth. Then, we washed the flasks with PBS and added fresh medium. The next day, we prepared the samples.

For layered conditions, we plated $52,500 \mathrm{cells} / \mathrm{cm}^{2}$ and covered them with a $1.5 \mathrm{~mm}$-thick hydrogel layer. As controls, we plated 52,500 cells $/ \mathrm{cm}^{2}$ on poly-L-lysine coated microplates. For embedded conditions, we mixed $105,000 \mathrm{cells} / \mathrm{cm}^{2}$ with the polymer solutions and plated $1.5 \mathrm{~mm}$-thick samples. For both conditions, after COLL fibrillogenesis we added culture medium and changed it every 2-3 days.

\section{$3 D$ cortical neurons and glial cells: embedded co-culture}

We harvested the cells as described, but at least one day after shaking, astrocytes were cultured in complete medium for cortical neurons, and to preserve the microglial cells, L-leucine methyl ester was not added. We mixed 32,000 glial cells $/ \mathrm{cm}^{2}$ and 315,000 cortical neurons $/ \mathrm{cm}^{2}$ with the polymer solutions and plated $1.5 \mathrm{~mm}$-thick samples. As controls, we co-cultured 13,200 glial cells/ $/ \mathrm{cm}^{2}$ and 242,000 neurons $/ \mathrm{cm}^{2}$ on poly-D-lysine coated microplates. After COLL fibrillogenesis, we added culture medium for cortical neurons and refreshed it (50\% v/v) every 3 days.

\section{Cell metabolic activity}

To assess the ability of hydrogel matrices to support brain cell survival, we examined cell metabolic activity by MTS assay (Promega, Madison, WI, USA). This was done on 
days 1, 2 and 5 for microglial cells; on days 7, 14 and 18 for cortical neurons in layered conditions; and on days 7 , 14 and 21 for the other conditions. We incubated the samples for $3 \mathrm{~h}$ with culture medium supplemented with $10 \%$ MTS, then measured their absorbance at $490 \mathrm{~nm}$. We used $1.5-\mathrm{mm}$ thick cell-free gels as control. We ran the assay on at least five samples/group for single cultures and ten samples/group for the co-culture.

\section{Immunocytochemistry and confocal imaging}

Immunocytochemistry was done to observe brain cell morphology and spatial distribution at the time points when we measured the highest cell metabolic activity for 2D controls (on day 2 for microglial cells, and on day 14 for cortical neurons, astrocytes and the co-culture).

We removed the culture medium, washed the samples with PBS and fixed them with paraformaldehyde solution (PFA, $4 \%$ in PBS), for $24 \mathrm{~h}$. We washed them with Trisbuffered saline supplemented with $0.1 \%$ Tween 20 (TBS$\mathrm{T})$, and blocked them $\left(8-9 \mathrm{~h}, 4^{\circ} \mathrm{C}\right)$ in TBS-T with $4 \%$ normal goat serum (NGS), $1 \mathrm{mg} / \mathrm{mL}$ bovine serum albumin (BSA), Tris $50 \mathrm{mM}, 0.1 \%$ gelatin and $0.3 \mathrm{M}$ glycine. After washing the samples with TBS-T, we incubated them $(20 \mathrm{~h}$, $4{ }^{\circ} \mathrm{C}$ ) with primary antibodies, then washed and incubated $\left(10 \mathrm{~h}, 4{ }^{\circ} \mathrm{C}\right)$ with secondary antibodies. We stained cell nuclei with $0.02 \mathrm{mM}$ Hoechst 33342 (Thermo Fisher Scientific) for observation with a confocal microscope (FV10i, Olympus, Tokyo, Japan). We stained microglial cells with anti-CD11b (1:8000, Biotechne, Minneapolis, $\mathrm{MN}$, USA), and anti-CD68, a pan-macrophage marker (1:200, Bio-Rad Laboratories, Hercules, CA, USA), cortical neurons with anti-neuron-specific $\beta$-tubulin III (Tuj-1, 1:500, Sigma-Aldrich), and astrocytes with anti-glial fibrillary acidic protein (GFAP, 1:3000, Millipore, Burlington, MA, USA). As secondary antibodies (1:500, Thermo Fisher Scientific) we used anti-mouse IgG Alexa Fluor ${ }^{\circledR} 488$, antimouse IgG Alexa Fluor $^{\circledR}$ 647, and anti-rabbit IgG Alexa Fluor $^{\circledR}$ 594. As controls, we examined cells in $2 \mathrm{D}$ conditions. Only for single cultures of microglial cells, on day 2 we investigated whether hydrogel presence elicited microglial activation by comparison with control cells previously incubated for $24 \mathrm{~h}$ with lipopolysaccharide (LPS, from Escherichia coli O111:B4, $1 \mathrm{ug} / \mathrm{ml}$, Sigma-Aldrich), a proinflammatory stimulus.

\section{Western Blotting}

To assess neuronal function, on days 7 and 14 we investigated synapse formation in single cultures of cortical neurons and in the co-culture. To examine the presence of astrocytes, we investigated GFAP expression in the coculture at the same time points.

We removed the culture medium, washed the samples with PBS, added lysis buffer (with $1 \%$ protease inhibitor cocktail), incubated them for $1 \mathrm{~h}$ at $4{ }^{\circ} \mathrm{C}$ and lysed them with a cell scraper. We vortexed them for about $1 \mathrm{~min}$, then centrifuged them at $4{ }^{\circ} \mathrm{C}$ for $5 \mathrm{~min}$ at maximum speed and collected the supernatants. To evaluate the effect of $3 \mathrm{D}$ embedded conditions on the basal levels of protein expression, we also examined controls in 2D conditions. In view of a possible interference from COLL, protein content was evaluated only for controls, by the bicinchoninic acid assay (BCA, Pierce ${ }^{\mathrm{TM}}$, Thermo Fisher). We separated protein extracts by SDS-PAGE and transferred them to a nitrocellulose membrane (Bio-Rad Laboratories). We incubated the membranes overnight at $4{ }^{\circ} \mathrm{C}$ with anti-postsynaptic density protein 95 (PSD-95, 1:5000, NeuroMab, Davis, CA, USA), anti-synaptophysin (a presynaptic protein, 1:5000, Synaptic System GmbH, Goettingen, Germany), anti-N-Methyl-D-Aspartate Receptor Subunit NR1 (NR-1, 1:1000, Synaptic System GmbH), anti-GFAP (1:10000), anti-Tuj-1 (1:5000) or glyceraldehyde 3-phosphate dehydrogenase (GADPH, 1:2000, Millipore). Then, we incubated the membranes with the secondary antibodies conjugated to the enzyme horseradish peroxidase. We covered the membranes with luminol solution (EMD Millipore), developed the immunoreactive bands with Firereader V10 PLUS 26M Imaging system (Uvitec Ltd, Cambridge, UK) and quantified them with Image Lab software. The analysis was done in triplicate.

\section{Statistics}

The results were reported as mean \pm standard deviation (SD) and analyzed with GraphPad Prism ${ }^{\circledR}$ software (GraphPad Software Inc, release 8.0). Two-way analysis of variance (ANOVA) was followed by Tukey's multiple comparisons test for comparisons of the groups and time frames. We considered $p<0.05$ significant.

\section{Results}

\section{D microglial cells}

In the absence of supporting cells like astrocytes, single cultures of primary microglial cells are viable for a very short time $\mathrm{e}^{39}$ and usually tested 48 to $72 \mathrm{~h}$ after plating. We therefore limited the evaluation of their metabolic activity to 5 days. However, this was sufficient to appreciate the benefits of hydrogels for extending their culture time.

In layered conditions, metabolic activity (upper panel, Figure 1(a)) was constant $(p>0.05)$ from day 1 to 2 for cells covered with COLL-HA gels, and it decreased with PEG-based gels. From day 2 to 5, it increased for all the matrices ( $p<0.0001$ for all comparisons). The significant increase on day 5 was due to the loss of viability of 2D controls (almost total absence of cells) and the general slowing of cell growth observed for the hydrogels. On day 2, confocal images (upper panel, Figure 1(b)) confirmed 


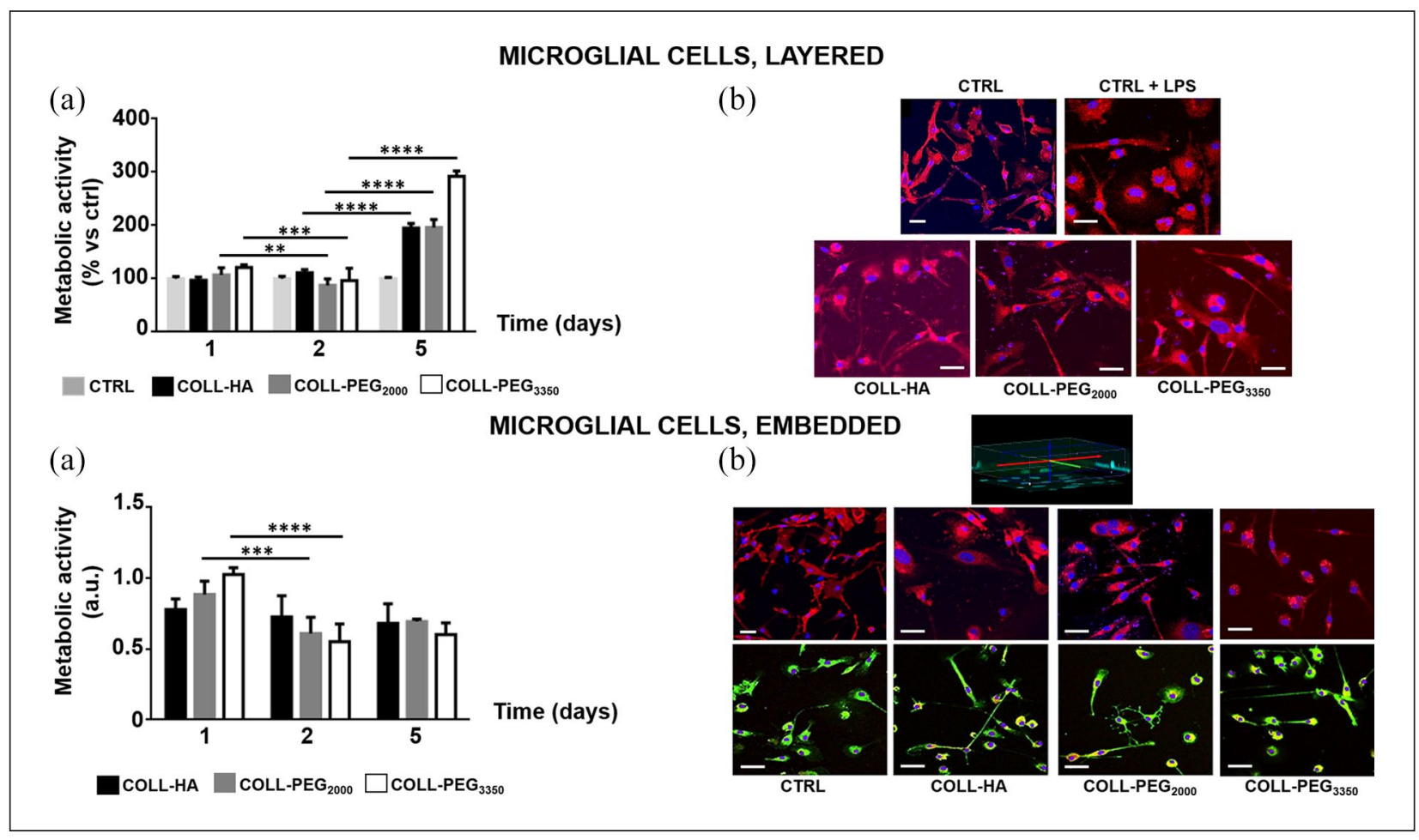

Figure I. Primary microglial cells in layered and embedded conditions. Layered conditions: (a) Cell metabolic activity over time for microglial cells covered with a $1.5 \mathrm{~mm}$-thick layer of COLL-HA, COLL-PEG 2000 or COLL-PEG ${ }_{3350}$ gels. The results are mean \pm SD with respect to 2D controls (CTRL), 5 replicates/condition. (b) Representative images of microglia immunostained for CDI Ib (red) and cell nuclei stained with Hoechst 33342 (blue) on day 2. As a reference, cells grown in 2D conditions and incubated with LPS (CTRL + LPS) were also immunostained. Scale bar: $20 \mu \mathrm{m}$.

Embedded conditions: (a) Cell metabolic activity over time for microglial cells embedded in 1.5 mm-thick COLL-HA, COLL-PEG ${ }_{2000}$ or COLL-PEG 3350 gels. The results are mean $\pm \mathrm{SD}, 5$ replicates/condition. (b) Representative images of microglia immunostained on day 2. Upper row: cells immunostained for CDI lb (red) and cell nuclei stained with Hoechst 33342 (blue); lower row: CDI Ib (green), CD-68 (red) and cell nuclei stained with Hoechst 33342 (blue). The morphology of CTRL is reported for comparison. Scale bar: $20 \mu \mathrm{m}$. For both conditions, cell metabolic activity was analyzed with ordinary two-way ANOVA followed by Tukey's multiple comparisons test.

$*_{p} p<0.01$ I; ${ }^{* *} p<0.001$ I; ${ }^{* * *} p<0.000$ I.

uniform cell distribution and nuclei staining indicated that cell number was comparable in all conditions. CD11b staining showed a larger number of branches in the presence of the hydrogels, suggesting the induction of microglial activation. PEG-based matrices showed greater microglial activation than COLL-HA ones, but still lower than positive controls treated with LPS.

In embedded conditions, cell metabolic activity (lower panel, Figure 1(a)) was constant $(p>0.05)$ over time for COLL-HA gels, while for PEG-based semi-IPNs it decreased from day 1 to 2 , and then remained constant $(p>0.05)$. CD11b staining (lower panel, Figure 1(b), first set of images) indicated that a few microglia presented a more branched morphology than controls. This suggests that microglial activation is almost absent in embedded conditions. We also assessed microglial phagocytic activity by CD68 staining (red in the second set of images in Figure 1(b)). In COLL-HA and COLL-PEG 2000 gels, we detected immunoreactivity in the cytoplasm of some microglia, indicating that cell morphology elicited an immune response. For controls and COLL-PEG ${ }_{3350}$ gels, activated cells were almost absent.

\section{D cortical neurons: Metabolic activity and immunocytochemistry}

Experimentally, neuronal cultures are usually employed within 14 days. However, extending this observation time may be important in the view of developing an OOC-based platform for prolonged cell culture and improving the in vitro recapitulation of pathological mechanisms. We therefore extended this target time up to 21 days.

In layered conditions (upper panel, Figure 2(a)), the gels reduced cell metabolic activity compared to 2D controls. Among the matrices, at all the time points PEG-based hydrogels performed best. On day 18, neurons covered with COLL-PEG ${ }_{3350}$ showed the greatest metabolic activity $(p<0.0001)$, while COLL-HA and COLL-PEG 2000 semi-IPNs gave comparable results $(p<0.05)$. On day 14 , for $2 \mathrm{D}$ controls and layered cells, Tuj-1 staining (upper 


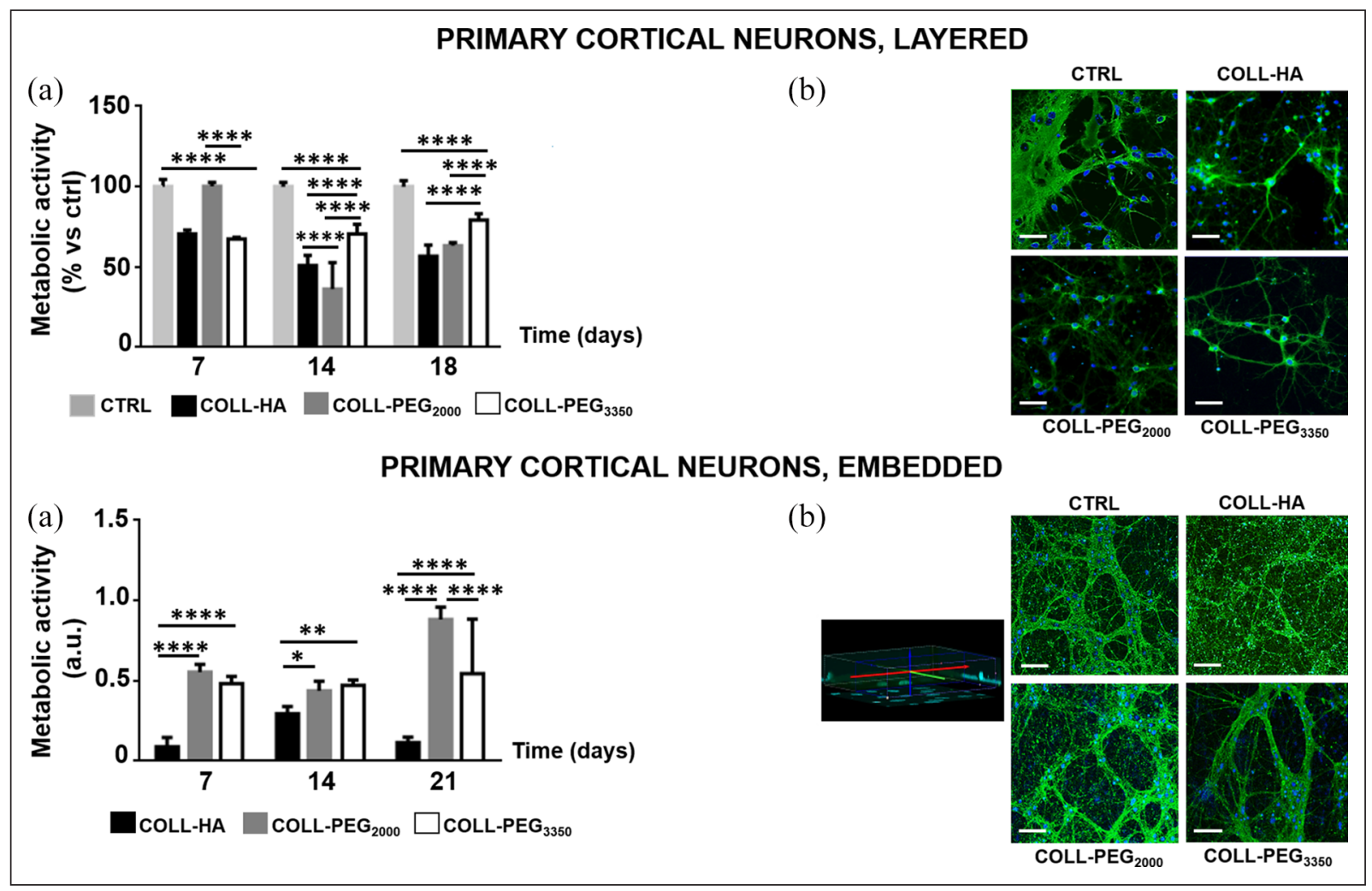

Figure 2. Primary cortical neurons in layered and embedded conditions. Layered conditions: (a) Cell metabolic activity over time for cortical neurons covered with a $1.5 \mathrm{~mm}$-thick layer of COLL-HA, COLL-PEG 2000 or COLL-PEG 3350 gels. The results are mean \pm SD with respect to 2D controls (CTRL), 8 replicates/condition. (b) Representative images of neurons immunostained for $\beta$-tubulin III (Tuj-I, green) and cell nuclei stained with Hoechst 33342 (blue) on day I4. Scale bar: $50 \mu \mathrm{m}$.

Embedded conditions: (a) Cell metabolic activity over time for cortical neurons embedded in I.5 mm-thick COLL-HA, COLL$\mathrm{PEG}_{2000}$ or COLL-PEG 3350 gels. The results are mean $\pm \mathrm{SD}, 5$ replicates/condition. (b) Representative images of neurons immunostained for $\beta$-tubulin III (green) and cell nuclei stained with Hoechst 33342 (blue) on day 14. The morphology of CTRL is reported for comparison. Scale bar: $50 \mu \mathrm{m}$. For both conditions, cell metabolic activity was analyzed with ordinary two-way ANOVA followed by Tukey's multiple comparisons test. $*_{p}<0.05 ; * * p<0.01 ; * * * p<0.0001$.

panel, Figure 2(b)) indicated the presence of articulated neuronal networks and uniform spatial distribution of neuronal extensions, with no aggregated branches. Control neurons had more complex networks. However, neurons covered with PEG-based gels showed more numerous extensions than controls and neurons in COLL-HA semi-IPNs.

Starting from these promising results, we extended the culture time to 21 days for the embedded condition (lower panel, Figure 2(a)). At all the time points, cell metabolic activity was lower for COLL-HA semi-IPNs. Differences between PEG-based gels were found only on day 21, with COLL-PEG $_{2000}$ performing best $(p<0.0001)$. On day 14 (lower panel, Figure 2(b)), 2D controls showed dense neuronal networks. Similar networks were observed in PEGbased semi-IPNs, where neuronal extensions penetrated the matrices and spread in all directions. For COLL-HA gels, MTS assay indicated viable neurons, but Tuj-1 staining showed the almost complete absence of neuronal extensions. DNA staining indicated smaller nuclei than in the other semi-IPNs, suggesting possible cell suffering. These results indicate that the embedded condition promotes the formation of more complex neuronal networks than the layered one. The embedded-based model represents a more physiologically relevant condition and allows cells to benefit from a larger surface area for growth. ${ }^{40}$

\section{D cortical neurons: Synapse formation}

To obtain dense, mature neuronal networks in vitro, generally about 10 days are required. ${ }^{41}$ We therefore studied the expression of PSD-95, synaptophysin, and NR-1 on days 7 and 14. Since it is a neuron-specific marker and it is not influenced by cell proliferation, we investigated synapse formation using $\beta$-tubulin III as the housekeeping protein. As stress or $3 \mathrm{D}$ culture conditions can influence cytoskeleton architecture and thus $\beta$-tubulin III expression, ${ }^{42}$ before quantification we performed Western blot analysis using GADPH as the housekeeping protein (data not shown). 


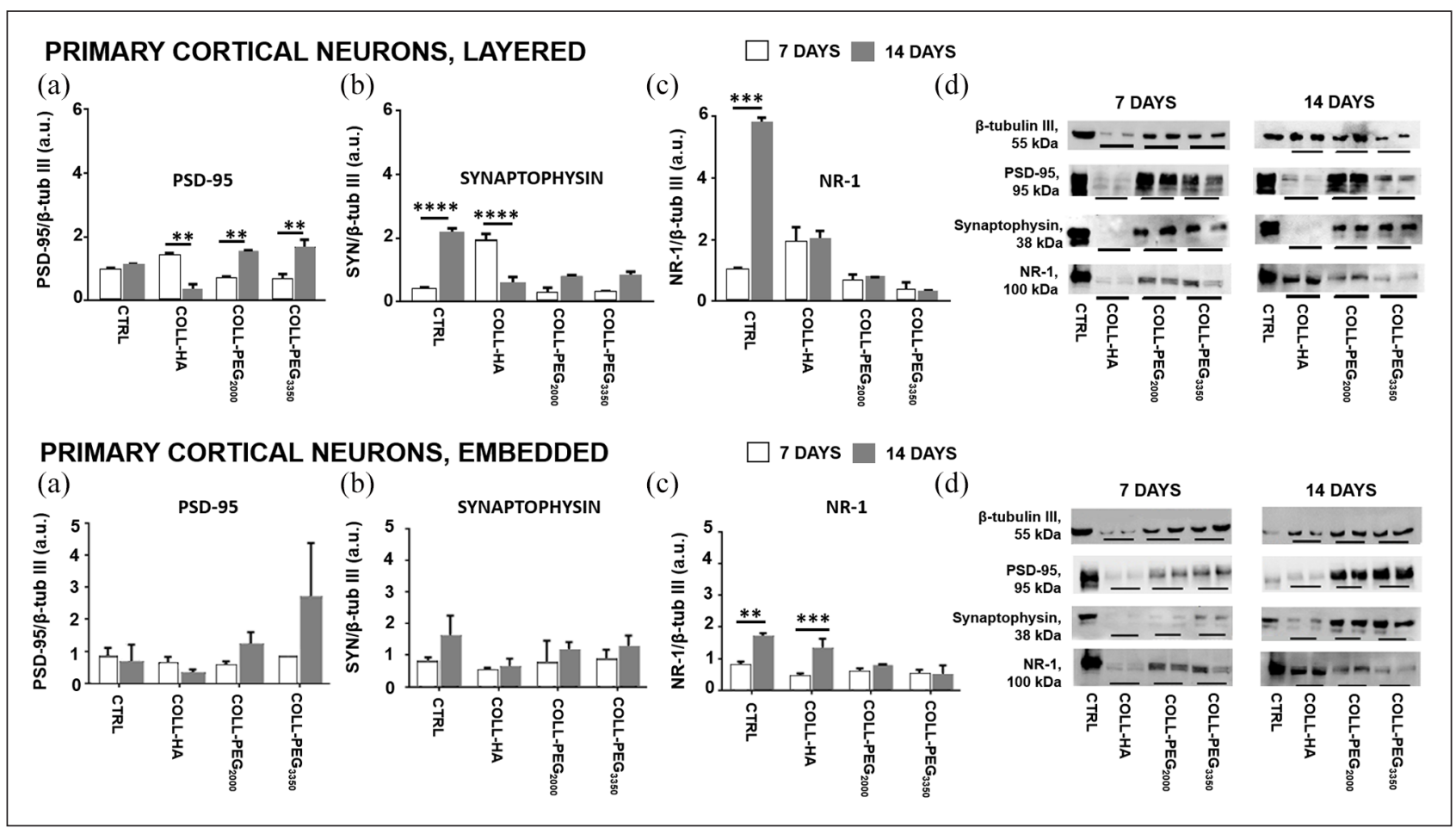

Figure 3. Immunoblots on primary cortical neurons in layered and embedded conditions. Layered conditions: Western blot quantification on days 7 and 14 to detect (a) PSD-95, (b) Synaptophysin, (c) NR-I, in cortical neurons covered with a 1.5 mm-thick layer of COLL-HA, COLL-PEG 2000 or COLL-PEG ${ }_{3350}$ gels. (d) Representative immunoblots used for the quantifications.

Embedded conditions: Western blot quantification on days 7 and 14 to detect (a) PSD-95, (b) Synaptophysin, (c) NR-I, in cortical neurons embedded in 1.5 mm-thick COLL-HA, COLL-PEG 2000 or COLL-PEG 3350 gels. (d) Representative immunoblots used for the quantifications.

The results (mean $\pm S D, 3$ replicates/condition) are also reported for 2D controls (CTRL) and normalized to $\beta$-tubulin III (Tuj-I). They were analyzed with ordinary two-way ANOVA followed by Tukey's multiple comparisons test. For CTRL, we loaded $20 \mu g$ total proteins, and for each hydrogel, we loaded $20 \mu \mathrm{L}$ total sample. $*_{p}<0.05 ; * * p<0.01$; ***p $<0.001$.

In layered conditions (upper panel, Figure 3(a)-(d)), the levels of PSD-95 rose from day 7 to 14 for PEG-based gels $(p<0.01)$, but decreased in the presence of COLL-HA $(p<0.01)$. In these matrices, the levels of synaptophysin also decreased $(p<0.0001)$. No differences in the levels of NR-1 were observed for the hydrogels.

In contrast, in embedded conditions (lower panel, Figure 3(a)-(d)), the levels of PSD-95 increased for PEG-based gels from day 7 to 14 , but it was not significant $(p>0.05)$. Similarly, for all the matrices the levels of synaptophysin did not change over time $(p>0.05)$. On the contrary, the levels of NR-1 rose for COLL-HA samples $(p<0.001)$.

\section{$3 D$ astrocytes}

For astrocytes in layered conditions (upper panel, Figure 4(a)), cell metabolic activity was lower than for 2D controls. For all the matrices, cell metabolic activity increased $(p<0.0001)$ between days 7 and 14, but the worst performances were for COLL-HA semi-IPNs. On day 21, metabolic activity was greatest for astrocytes layered with
PEG-based gels $(p<0.0001)$. On day 14 , confocal images (upper panel, Figure 4(b)) showed uniform cell distribution. For astrocytes covered with COLL-HA gels, nuclear staining indicated a cell number comparable to the other conditions, but GFAP staining suggested that astrocytes had a limited, undeveloped morphology compared to their counterparts covered by PEG-based gels.

In embedded conditions (lower panel, Figure 4(a)), cell metabolic activity was greatest for COLL-HA semi-IPNs $(p<0.0001)$ and no differences were found between PEG-based gels. This suggests slower astrocyte proliferation in PEG-based matrices. Like in layered conditions, on day 14 confocal images (lower panel, Figure 4(b)) showed uniform cell distribution within the gels. In COLL-HA semi-IPNs, nuclei staining indicated a higher cell number than in 2D controls and PEG-based matrices, but GFAP staining suggested that COLL-HA gels disadvantaged astrocytic branching. There were some differences between astrocyte morphology in controls and PEG-based gels, but growth in 3D matrices seemed slower than in $2 \mathrm{D}$ conditions. 


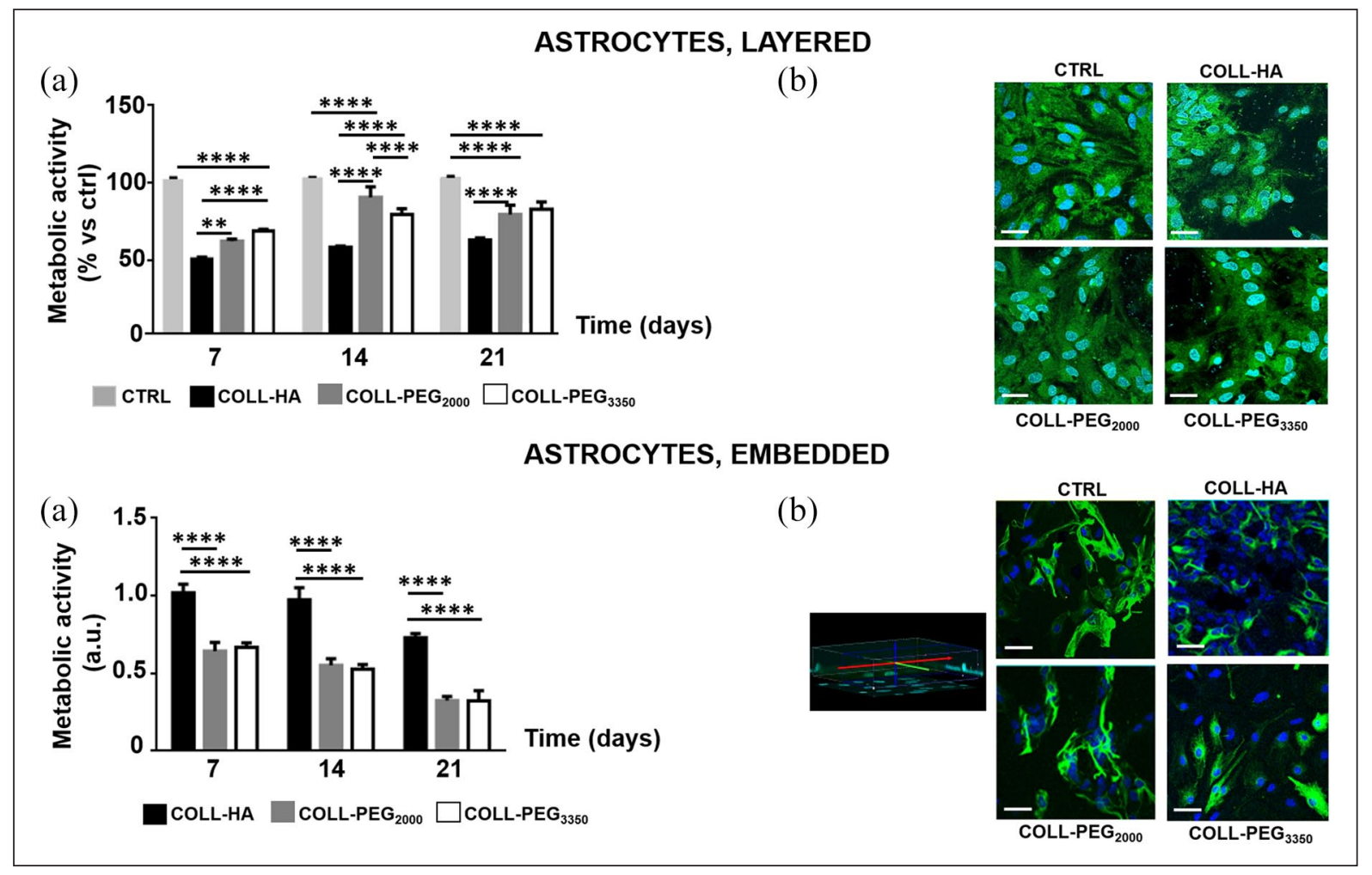

Figure 4. Primary astrocytes in layered and embedded conditions. Layered conditions: (a) Cell metabolic activity over time for astrocytes covered with a $1.5 \mathrm{~mm}$-thick layer of COLL-HA, COLL-PEG 2000 or COLL-PEG ${ }_{3350}$ gels. The results are mean \pm SD with respect to 2D controls (CTRL), 5 replicates/condition. (b) Representative images of astrocytes immunostained for GFAP (green) and cell nuclei stained with Hoechst 33342 (blue) on day I4. Scale bar: $50 \mu \mathrm{m}$.

Embedded conditions: (a) Cell metabolic activity over time for astrocytes embedded in 1.5 mm-thick COLL-HA, COLL-PEG 2000 or COLL-PEG $_{3350}$ gels. The results are mean \pm SD, 5 replicates/condition. (b) Representative images of astrocytes immunostained for GFAP (green) and cell nuclei stained with Hoechst 33342 (blue) on day 14. The morphology of CTRL is reported for comparison. Scale bar: $50 \mu \mathrm{m}$. For both conditions, metabolic activity was analyzed with ordinary two-way ANOVA followed by Tukey's multiple comparisons test.

$* * p<0.01 ; * * * * p<0.0001$.

\section{D neurons and glial cells: Co-culture (metabolic activity and immunocytochemistry)}

The previous results indicated that the embedded-based model promotes the formation of more complex neuronal networks and considerably reduces microglial activation. We therefore selected this condition to develop a 3D brainlike tissue model based on the co-culture of cortical neurons and glial cells.

In COLL-HA gels, cell metabolic activity (Figure 5(a)) was constant from day 7 to 14 ( $p>0.05$ ), then it decreased $(p<0.01)$. In PEG-based matrices, it decreased from day 7 to $14(p<0.0001)$, then it rose $(p<0.05$ for COLL$\mathrm{PEG}_{2000} ; p<0.001$ for COLL-PEG 3350 ). On day 21, COLL-PEG 3350 semi-IPNs performed best.

On day 14, confocal imaging showed the presence of complex networks (Figure 5(b)), where glial cells and neurons can communicate. GFAP staining indicated that astrocytes supported neuronal cells, while Tuj-1 staining showed that neural networks are denser than in single cultures. However, spatial organization was more complex in COLL-PEG 2000 gels. In agreement with nuclear staining, in COLL-HA and COLL-PEG ${ }_{3350}$ matrices, Tuj-1 staining revealed less dense and structured neuronal networks, while GFAP staining showed that glial cells were only partially dedicated to neuronal support.

\section{D neurons and glial cells: Co-culture (synapse formation)}

When co-culturing neurons and glial cells, we measured the levels of synaptic markers in the semi-IPNs at 7 and 14 days (Figure 6(a)-(d)). These suggest that the selected culture conditions permit the maintenance of the key biochemical parameters of the embedded cell populations for a considerable time. In most cases (e.g. PSD-95 in COLL$\mathrm{PEG}_{3350}$, synaptophysin in COLL-PEG 2000 and NR-1 in COLL-HA gels), we confirmed the previous results for single cultures of cortical neurons in embedded conditions. Furthermore, the changes in expression levels were greater in co-culture conditions than in single cultures. However, for COLL-HA gels protein content was lower than for PEG-based gels (Figure 6(e)). This agrees with previous 


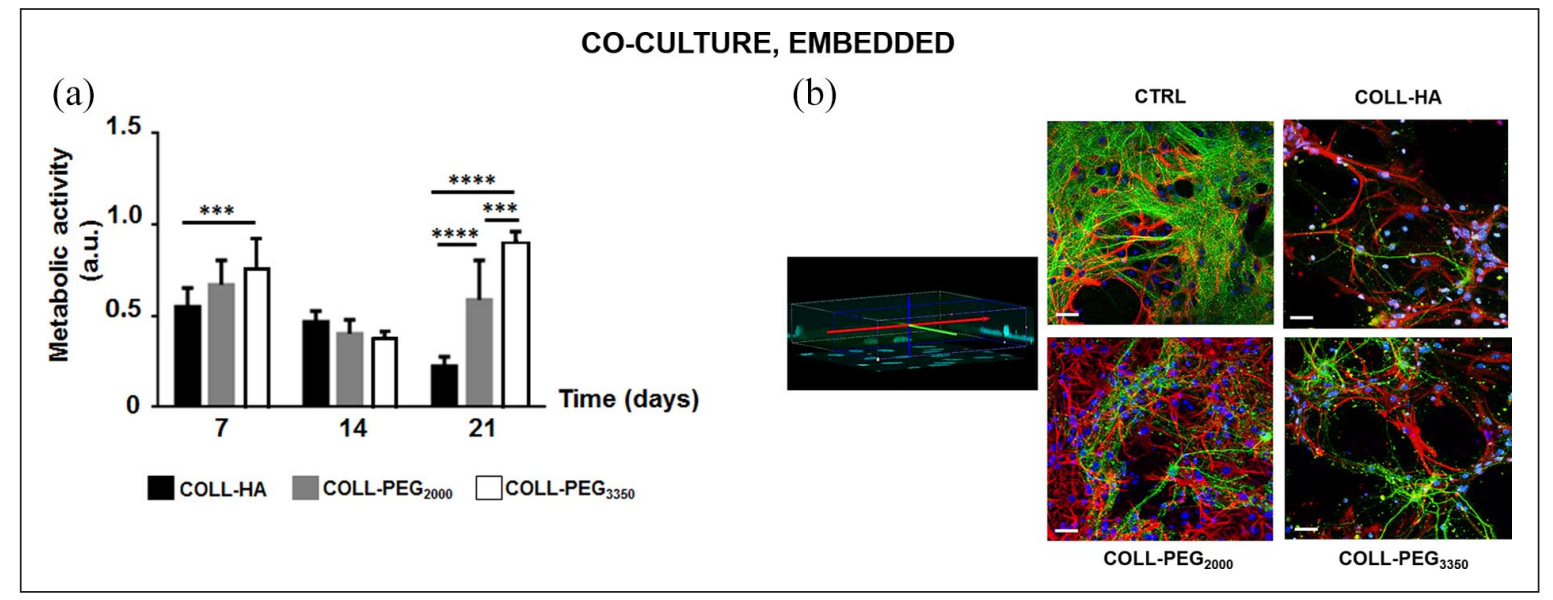

Figure 5. Co-cultures of cortical neurons and glial cells. (a) Cell metabolic activity over time for cortical neurons and glial cells embedded in 1.5 mm-thick COLL-HA, COLL-PEG 2000 or COLL-PEG 3350 gels. The results are mean \pm SD, 10 replicates/condition. The results were analyzed with ordinary two-way ANOVA followed by Tukey's multiple comparisons test. (b) Representative images of embedded neurons immunostained for $\beta$-tubulin III (Tuj-I, green), astrocytes immunostained for GFAP (red) and cell nuclei stained with Hoechst 33342 (blue) on day 14. The morphology of CTRL was reported for comparison. Some nuclei whose cell body was not reactive either to Tuj-I or GFAP are present, likely belonging to microglial cells. Scale bar: $20 \mu \mathrm{m}$.

$* * * p<0.001 ; * * * * p<0.0001$.

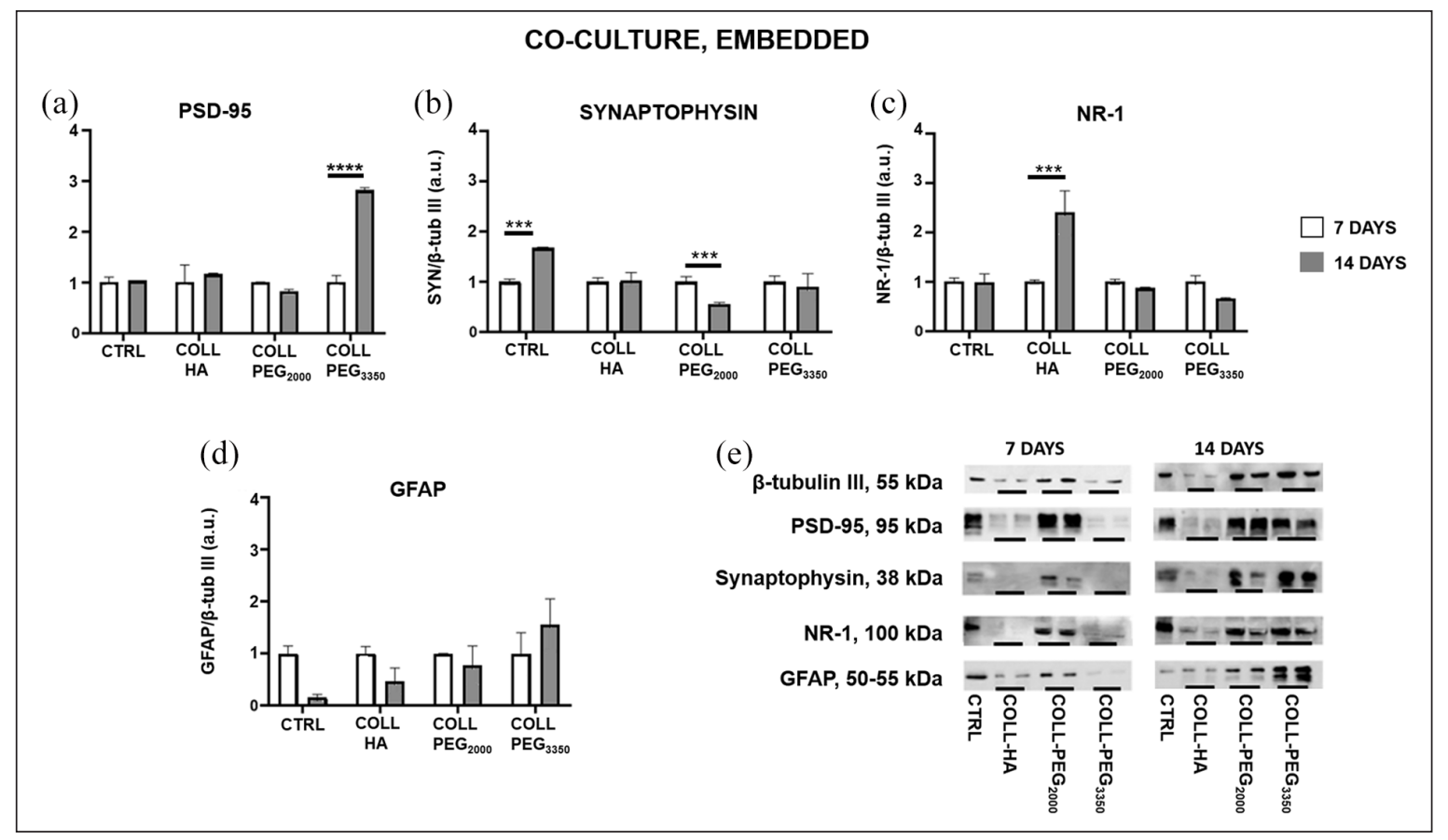

Figure 6. Immunoblots on co-cultures of cortical neurons and glial cells. Western blot quantification on days 7 and 14 to detect (a) PSD-95, (b) Synaptophysin, (c) NR-I, (d) GFAP, in co-cultures of cortical neurons and glial cells embedded in $1.5 \mathrm{~mm}$-thick COLL-HA, COLL-PEG 2000 or COLL-PEG 3350 gels. The results (mean \pm SD, 3 replicates/condition) are also reported for 2D controls (CTRL) and normalized to $\beta$-tubulin III (Tuj-I). They were analyzed with ordinary two-way ANOVA followed by Tukey's multiple comparisons test. (e) Representative immunoblots used for quantification. For CTRL, we loaded $20 \mu g$ total protein, and for each hydrogel, we loaded $20 \mu \mathrm{L}$ total sample. $* * * p<0.001$; ****p $<0.0001$.

results from cell metabolic activity (Figure 5(a)), but suggests a poor quality of the culture. In COLL-PEG ${ }_{3350}, \beta$ tubulin III expression was low on day 7, suggesting slower neuronal maturation than in COLL-PEG ${ }_{2000}$ matrices. However, it rose significantly on day 14. In COLL-PEG 2000 gels, $\beta$-tubulin III increased slightly between days 7 and 
14, indicating that these semi-IPNs are more promising to reach the target culture time of 21 days.

To investigate the balance between neurons and glial cells over time, we measured the expression levels of GFAP from days 7 to 14 and noted an increase (although not significant) only for COLL-PEG 3350 matrices (Figure 6(d)). These results confirm that this matrix promotes astrocyte proliferation, but in the time window examined glial cells do not take over the neuronal network.

\section{Discussion}

The bidirectional communication between intestinal microbiota and the brain, referred to as MGBA, has attracted growing interest also for its clinical potential, such as exploiting microbiota-based therapeutics as new strategies to manage neurological diseases and behavioral functions. Several challenges remain before clinical translation, ${ }^{43}$ but a reliable $\mathrm{OOC}$ platform recapitulating in vitro the main players of the MGBA may offer an effective tool to clarify the impact of intestinal microbiota on brain functions, in physiological and pathological conditions. In this perspective, developing an OOC-based 3D system modeling brain tissue is particularly challenging. ${ }^{4}$

Starting from the scalability of the thickness of COLLbased semi-IPNs to the millimeter scale and their suitability for dynamic culture in a microfluidic, optically accessible OOC device, ${ }^{5}$ we set up a novel 3D brain-like tissue model potentially suitable for dynamic culture by coupling $1.5 \mathrm{~mm}$-thick COLL-based semi-IPNs to the coculture of cortical neurons and glial cells. Semi-IPNs have the advantage of easy tunability of their final properties ${ }^{35}$ a key point when aiming at co-culturing different cell types, including neural cells.

Initially, we investigated the biocompatibility of the COLL-based semi-IPNs with primary mouse microglia, neurons and astrocytes as single cultures. Compared to Matrigel, widely exploited as a scaffold material for neural cells, ${ }^{39,44,45}$ COLL has a more defined composition and has also been successfully applied for brain cultures. ${ }^{46,47}$

Since different 3D culture conditions are reported ${ }^{31,32}$ and their advantages depend on the application, ${ }^{48}$ we considered both a layered-based model, where cells are covered by the hydrogel, and an embedded-based model, where cells are uniformly dispersed in the $3 \mathrm{D}$ volume. In both conditions, neurons maintained their phenotype and showed more interconnected networks than in 2D cultures. However, more complex neuronal networks and the absence of microglial activation due to the hydrogel were found in the embedded condition, indicating that it is preferable. We therefore co-cultured neurons and glial cells only in the embedded-based situation. For both embedded neurons and microglial cells, PEG-based gels performed better. In COLL-HA semi-IPNs, neuron viability was reduced, as indicated by the failure to emit extensions and build a complex network in confocal imaging and the low expression of synaptic proteins. However, astrocytes proliferated more in COLL-HA semi-IPNs. This is a key point with a view to co-culturing neurons and glial cells, since excessive astrocyte proliferation could hinder neuronal survival. With this in mind, PEG-based formulations may be the best-balanced solution also for astrocyte culture.

The importance of astrocyte-neuron ratio was reported by Fang and colleagues, who showed that the spatial relationships between neurons and astrocytes affect neuronal growth and functions. ${ }^{48}$ To mimic the ratio between the number of glial cells and neurons in the natural brain cortex, ${ }^{49}$ they co-cultured astrocytes and neurons on a $1: 2$ ratio for 14 days and showed that neurons benefited from astrocytes when these were confined by the neurons. In contrast, in the embedded condition, astrocytes overexpanded and hindered neuronal growth. ${ }^{49}$ To avoid this, in the co-culture we used fewer glial cells than in single cultures and optimized a ratio of 1:10 between glial cells and neurons. This ratio was also considered in other studies, for instance with induced-pluripotent stem cells (iPSC). ${ }^{50}$

An important point when developing 3D brain cell models is to achieve sufficiently long-lasting viability to allow cell maturation and full differentiation. In our models, MTS assay confirmed cell viability up to 21 days, with a better performance for PEG-based gels. Although metabolic activity was greater for cells in COLL-PEG ${ }_{3350}$, we suggest COLL-PEG ${ }_{2000}$ as the best option for the full 3D model because of the better structured neuron/glia networks. For this reason, it appeared as the most promising candidate for a 3D brain-like tissue model and would also be suitable to study the impact of intestinal microbiota on brain function in an OOC device. However, a further characterization of the model is mandatory, in particular by performing microglia immunostaining with suitable antibodies (e.g., CD11b or Iba1).

From the cell model point of view, primary cells are more physiological than continuous cell lines and have some advantages in terms of costs and reproducibility compared to other systems, such as those based on stem cells. The literature reports several examples of 3D brainlike tissue models exploiting stem cells, where cell differentiation is achieved with differentiation media or based on a combination of hydrogel formulation and final mechanical properties. ${ }^{51-53}$ Recent works have focused on iPSC, which can be differentiated into neural progenitor cells, and then various CNS-related cell phenotypes. They are excellent candidates for personalized medicine ${ }^{54}$ and disease modeling. ${ }^{55-57}$ For instance, starting from the work by Choi et al., ${ }^{40}$ Park et al. employed iPSC to successfully reproduce dynamic neural-glial interactions in a microfluidic device and recapitulate key features of Alzheimer's disease, such as beta-amyloid accumulation, phosphorylated tau aggregation and neuroinflammation. ${ }^{57}$ 
However, the differentiation of iPSC-derived progenitor or precursor cells is hard to control, ${ }^{58}$ and iPSC-derived neuronal cells are still not suitable for time-consuming optimization studies such as the one presented here, because they are expensive. Furthermore, although the differentiation protocols have been optimized to confirm the nature of post-differentiation cells in terms of functionality and morphology, the technologies still need improvements to boost reproducibility. ${ }^{59}$ In the future, the use of commercial iPSC-derived microglial cells will extend the limited culture time of their primary counterparts, thus overcoming a current limitation of our study and improving the predictability of the 3D systems. Abud et al. described the generation of highly pure iPSC-derived human microglial-like cells similar to both fetal and adult microglia to study their functions in physiological and pathological conditions, like Alzheimer's disease.$^{60}$

When recapitulating brain physiology at the molecular and functional levels, key points are the evaluation of synaptic proteins, suggesting the maturation of the neural network, and the recording of electrophysiological activity. For electroactive cells in 2D conditions, the recording of electrophysiological activity is widely consolidated, ${ }^{32,61}$ while the development and optimization of electrodes and stimulation/recording devices for cells in 3D conditions is an active research field. Since the possibility of stimulating or recording relies on close proximity to the electrodes, the thickness of the culture system is important for the feasibility and reliability of the acquisition. Commercial electrodes penetrate 50 to $100 \mu \mathrm{m}$ into the tissue, but electrophysiological measurements are reported for thicker systems. Frega et al. stacked 5-8 layers of microbeads with diameter about $40 \mu \mathrm{m}$ and hippocampal neurons, ${ }^{62}$ while recently Soscia et al. developed and validated an integrated 3D microelectrode array ${ }^{63}$ for applications with 750 to $1000 \mu \mathrm{m}$-thick cell-loaded hydrogels. For our goals, we preliminarily investigated our 3D brain-like models using a standard electrophysiology apparatus with a patch-clamp setup, but the background noise was too high to distinguish signals from the embedded cells. Thus, further experiments and technical improvements are still needed.

\section{Conclusions}

We developed an in vitro physiological brain-like tissue model based on $1.5 \mathrm{~mm}$-thick hydrogels and primary neuronal cells, also co-cultured, in both layered and embedded conditions. It provides a 3D model for setting up a brain compartment to be inserted into a complex OOC platform recapitulating brain functional relationship with peripheral body districts, as in the MGBA, in pathological and physiological conditions.

Future developments will focus on exploiting these results to develop a 3D, iPSC-based, brain-like tissue model, also for investigating Alzheimer's disease.

\section{Acknowledgements}

The authors are very grateful to Elena Restelli and Paola Fabbrizio (Istituto di Ricerche Farmacologiche Mario Negri IRCSS, Milan) for useful suggestions about cell culturing. We also thank Felice Volpe (Altergon Italia srl, Morra De Sanctis, Italy; currently at IBSA Institut Biochimique SA. Lugano, Switzerland) for suggestions about HA handling and processing and Dr. Judith Baggott for her skilled English editing.

\section{Author contributions}

IR, DA and CG conceived the study. IR carried out the experiments with support from MT for hydrogel preparation. IR and MT wrote the manuscript. GF made the equipment at the Dept. Neuroscience, Istituto di Ricerche Farmacologiche Mario Negri IRCCS, available for the experiments. DA and CG supervised the present manuscript and the related project activities. All authors discussed the results and approved the final manuscript.

\section{Declaration of conflicting interests}

The author(s) declared no potential conflicts of interest with respect to the research, authorship, and/or publication of this article.

\section{Funding}

The author(s) disclosed receipt of the following financial support for the research, authorship, and/or publication of this article: This study was funded by the European Research Council (ERC) under the European Union's Horizon 2020 research and innovation program (G.A. 724734-MINERVA) to CG. The results reflect only the authors' views and the Agency is not responsible for any use that may be made of the information contained.

\section{ORCID iD}

Marta Tunesi (iD https://orcid.org/0000-0003-2507-6186

\section{References}

1. Sherwin E, Rea K, Dinan TG, et al. A gut (microbiome) feeling about the brain. Curr Opin Gastroenterol 2016; 32(2): 96-102.

2. Lerner A, Neidhöfer S and Matthias T. The gut microbiome feelings of the brain: a perspective for non-microbiologists. Microorganisms 2017; 5(4): 66.

3. Farzi A, Fröhlich EE and Holzer P. Gut microbiota and the neuroendocrine system. Neurotherapeutics 2018; 15(1): 5-22.

4. Raimondi I, Izzo L, Tunesi M, et al. Organ-On-A-Chip in vitro models of the brain and the blood-brain barrier and their value to study the Microbiota-Gut-Brain Axis in neurodegeneration. Front Bioeng Biotechnol 2020; 7: 435.

5. Tunesi M, Izzo L, Raimondi I, et al. A miniaturized hydrogel-based in vitro model suitable for dynamic culturing of human cells overexpressing beta-amyloid precursor protein. J Tissue Eng 2020; 11: 1-17.

6. Huh D, Hamilton GA and Ingber DE. From 3D cell culture to organs-on-chips. Trends Cell Biol 2011; 21(12): 745754.

7. Moyer MW. Organs-on-a-Chip. Sci Am 2011; 304(3): 19. 
8. Rothbauer M, Rosser JM, Zirath H, et al. Tomorrow today: organ-on-a-chip advances towards clinically relevant pharmaceutical and medical in vitro models. Curr Opin Biotechnol 2019; 55: 81-86.

9. Irons HR, Cullen DK, Shapiro NP, et al. Three-dimensional neural constructs: a novel platform for neurophysiological investigation. J Neural Eng 2008; 5(3): 333-341.

10. Frampton JP, Hynd MR, Shuler ML, et al. Fabrication and optimization of alginate hydrogel constructs for use in 3D neural cell culture. Biomed Mater 2011; 6(1): 015002.

11. Kunze A, Giugliano M, Valero A, et al. Micropatterning neural cell cultures in 3D with a multi-layered scaffold. Biomaterials 2011; 32(8): 2088-2098.

12. Ren M, Du C, Herrero Acero E, et al. A biofidelic 3D culture model to study the development of brain cellular systems. Sci Rep 2016; 6(1): 24953.

13. Paşca SP. Assembling human brain organoids. Science 2019; 363(6423):126-127.

14. Koo B, Choi B, Park H, et al. Past, present, and future of brain organoid technology. Mol Cells 2019; 42(9): 617-627.

15. Korhonen P, Malm T and White AR. 3D human brain cell models: New frontiers in disease understanding and drug discovery for neurodegenerative diseases. Neurochem Int 2018; 120: 191-199.

16. Camp JG, Badsha F, Florio M, et al. Human cerebral organoids recapitulate gene expression programs of fetal neocortex development. Proc Natl Acad Sci U S A 2015; 112(51): 15672-15677.

17. Yin $X$, Mead BE, Safaee H, et al. Engineering stem cell organoids. Cell Stem Cell 2016; 18(1): 25-38.

18. Tomaskovic-Crook E and Crook JM. Clinically amendable, defined, and rapid induction of human brain organoids from induced pluripotent stem cells. Methods Mol Biol 2019; 1576: 13-22.

19. George J, Hsu CC, Nguyen LTB, et al. Neural tissue engineering with structured hydrogels in CNS models and therapies. Biotechnol Adv. Epub ahead of print March 2019. DOI: 10.1016/j.biotechadv.2019.03.009.

20. Engler AJ, Sen S, Sweeney HL, et al. Matrix elasticity directs stem cell lineage specification. Cell 2006; 126(4): 677-689.

21. Saha K, Keung AJ, Irwin EF, et al. Substrate modulus directs neural stem cell behavior. Biophys $J$ 2008; 95(9): 4426-4438.

22. Balgude AP, Yu X, Szymanski A, et al. Agarose gel stiffness determines rate of DRG neurite extension in 3D cultures. Biomaterials 2001; 22(10): 1077-1084.

23. Willits RK and Skornia SL. Effect of collagen gel stiffness on neurite extension. J Biomater Sci Polym Ed 2004; 15(12): 1521-1531.

24. Gunn JW, Turner SD and Mann BK. Adhesive and mechanical properties of hydrogels influence neurite extension. $J$ Biomed Mater Res A 2005; 72(1): 91-97.

25. Watanabe K, Nakamura M, Okano H, et al. Establishment of three-dimensional culture of neural stem/progenitor cells in collagen Type-1 Gel. Restor Neurol Neurosci 2007; 25(2): 109-117.

26. Pires LR, Rocha DN, Ambrosio L, et al. The role of the surface on microglia function: implications for central nervous system tissue engineering. $J$ R Soc Interface 2015; 12(103): 20141224.
27. Tremblay MÈ, Lowery RL and Majewska AK. Microglial interactions with synapses are modulated by visual experience. PLoS Biol 2010; 8(11): e1000527.

28. Schafer DP, Lehrman EK, Kautzman AG, et al. Microglia sculpt postnatal neural circuits in an activity and complement-dependent manner. Neuron 2012; 74(4): 691-705.

29. David S and Kroner A. Repertoire of microglial and macrophage responses after spinal cord injury. Nat Rev Neurosci 2011; 12(7): 388-399.

30. Leung BK, Biran R, Underwood CJ, et al. Characterization of microglial attachment and cytokine release on biomaterials of differing surface chemistry. Biomaterials 2008; 29(23): 3289-3297.

31. Ylä-Outinen L, Joki T, Varjola M, et al. Three-dimensional growth matrix for human embryonic stem cell-derived neuronal cells. J Tissue Eng Regen Med 2014; 8(3): 186-194.

32. Xu T, Molnar P, Gregory C, et al. Electrophysiological characterization of embryonic hippocampal neurons cultured in a 3D collagen hydrogel. Biomaterials 2009; 30(26): 4377-4383.

33. Balasubramanian S, Packard JA, Leach JB, et al. Threedimensional environment sustains morphological heterogeneity and promotes phenotypic progression during astrocyte development. Tissue Eng Part A 2016; 22(1112): 885-898.

34. Tunesi M, Batelli S, Rodilossi S, et al. Development and analysis of semi-interpenetrating polymer networks for brain injection in neurodegenerative disorders. Int $J$ Artif Organs 2013; 36(11): 762-774.

35. Tunesi M, Raimondi I, Russo T, et al. Hydrogel-based delivery of Tat-fused protein Hsp70 protects dopaminergic cells in vitro and in a mouse model of Parkinson's disease. NPG Asia Mater 2019; 11(1): 1-15.

36. Saura J, Tusell JM and Serratosa J. High-yield isolation of murine microglia by mild trypsinization. Glia 2003; 44(3): 183-189.

37. Apolloni S, Parisi C, Pesaresi MG, et al. The NADPH oxidase pathway is dysregulated by the $\mathrm{P} 2 \mathrm{X} 7$ receptor in the SOD1-G93A microglia model of amyotrophic lateral sclerosis. J Immunol 2013; 190(10): 5187-5195.

38. Restelli E, Fioriti L, Mantovani S, et al. Cell type-specific neuroprotective activity of untranslocated prion protein. PLoS One 2010; 5(10): e13725.

39. Bohlen CJ, Bennett FC, Tucker AF, et al. Diverse requirements for microglial survival, specification, and function revealed by defined-medium cultures. Neuron 2017; 94(4): 759-773.e8.

40. Choi SH, Kim YH, Hebisch M, et al. A three-dimensional human neural cell culture model of Alzheimer's disease. Nature 2014; 515(7526): 274-278.

41. Pani G, Samari N, Quintens R, et al. Morphological and physiological changes in mature in vitro neuronal networks towards exposure to short-, middle- or long-term simulated microgravity. PLoS One 2013; 8(9): e73857.

42. Edmondson R, Adcock AF and Liju Y. Influence of matrices on 3D-cultured prostate cancer cells' drug response and expression of drug-action associated proteins. PLoS One 2016; 11(6): e0158116.

43. Mimee M, Citorik RJ and Lu TK. Microbiome therapeutics - advances and challenges. Adv Drug Deliv Rev 2016; 105 : $44-54$. 
44. Yan W, Liu W, Qi J, et al. A three-dimensional culture system with matrigel promotes purified spiral ganglion neuron survival and function in vitro. Mol Neurobiol 2018; 55(3): 2070-2084.

45. Wang J, Chu R, Ni N, et al. The effect of Matrigel as scaffold material for neural stem cell transplantation for treating spinal cord injury. Sci Rep 2020; 10(1): 2576.

46. Kothapalli CR and Kamm RD. 3D matrix microenvironment for targeted differentiation of embryonic stem cells into neural and glial lineages. Biomaterials 2013; 34(25): 5995-6007.

47. Bourke JL, Quigley AF, Duchi S, et al. Three-dimensional neural cultures produce networks that mimic native brain activity. J Tissue Eng Regen Med 2018; 12(2): 490-493.

48. Fang A, Li D, Hao Z, et al. Effects of astrocyte on neuronal outgrowth in a layered 3D structure. Biomed Eng Online 2019; 18(1): 74 .

49. Herculano-Houzel S. The glia/neuron ratio: how it varies uniformly across brain structures and species and what that means for brain physiology and evolution. Glia 2014; 62(9): 1377-1391.

50. Tukker AM, Wijnolts FMJ, de Groot A, et al. Human iPSCderived neuronal models for in vitro neurotoxicity assessment. Neurotoxicology 2018; 67: 215-225.

51. Seidlits SK, Khaing ZZ, Petersen RR, et al. The effects of hyaluronic acid hydrogels with tunable mechanical properties on neural progenitor cell differentiation. Biomaterials 2010; 31(14): 3930-3340.

52. Aurand ER, Wagner JL, Shandas R, et al. Hydrogel formulation determines cell fate of fetal and adult neural progenitor cells. Stem Cell Res 2014; 12(1): 11-23.

53. Knowlton $\mathrm{S}$, Cho Y, Li XJ, et al. Utilizing stem cells for three-dimensional neural tissue engineering. Biomater Sci 2016; 4(5): 768-784.
54. Walker MJ, Bourke J and Hutchison K. Evidence for personalised medicine: mechanisms, correlation, and new kinds of black box. Theor Med Bioeth 2019; 40(2): 103-121.

55. Peng SP and Copray S. Comparison of human primary with human iPS cell-derived dopaminergic neuron grafts in the rat model for Parkinson's disease. Stem Cell Rev Rep 2016; 12(1): 105-120.

56. Zhang ZN, Freitas BC, Qian H, et al. Layered hydrogels accelerate iPSC-derived neuronal maturation and reveal migration defects caused by $\mathrm{MeCP} 2$ dysfunction. Proc Natl Acad Sci U S A 2016; 113(12): 3185-3190.

57. Park J, Wetzel I, Marriott I, et al. A 3D human triculture system modeling neurodegeneration and neuroinflammation in Alzheimer's disease. Nat Neurosci 2018; 21(7): 941-951.

58. Wu S, Xu R, Duan B, et al. Three-dimensional hyaluronic acid hydrogel-based models for in vitro human iPSCderived NPC culture and differentiation. J Mater Chem B 2017; 5(21): 3870-3878.

59. Farkhondeh A, Li R, Gorshkov K, et al. Induced pluripotent stem cells for neural drug discovery. Drug Discov Today 2019; 24(4): 992-999.

60. Abud EM, Ramirez RN, Martinez ES, et al. iPSC-derived human microglia-like cells to study neurological diseases. Neuron 2017; 94(2): 278-293.

61. Gouwens NW, Sorensen SA, Berg J, et al. Classification of electrophysiological and morphological neuron types in the mouse visual cortex. Nat Neurosci 2019; 22(7): 1182-1195.

62. Frega M, Tedesco M, Massobrio P, et al. Network dynamics of 3D engineered neuronal cultures: a new experimental model for in-vitro electrophysiology. Sci Rep 2014; 4: 5489.

63. Soscia DA, Lam D, Tooker AC, et al. A flexible 3-dimensional microelectrode array for in vitro brain models. $L a b$ Chip 2020; 20(5): 901-911. 